\title{
ПРОБЛЕМЫ ОБЕСПЕЧЕНИЯ ПСИХОЛОГИЧЕСКОЙ БЕЗОПАСНОСТИ РАБОТНИКОВ НА РАБОЧИХ МЕСТАХ В ПРОЦЕССЕ ИСПОЛНЕНИЯ ИМИ ПРОФЕССИОНАЛЬНЫХ ОБЯЗАННОСТЕЙ
}

Аннотация. В статье говорится о том, что реформы в сфере регулирования социально-трудовых отношений, проводимые в современной России, не уделяют внимания предупреждению и предотвращению «моббинга» — морального преследования работников на рабочем месте в процессе исполнения ими профессиональных обязанностей. Отчасти это обусловливается тем, что в современной России проблема активного преследования личности, занятой трудовой деятельностью, мало обсуждается, а вопрос совершенствования трудового законодательства в целях централизованного предупреждения «моббинга» не находит всестороннего теоретического осмысления. В связи с этим видится закономерным, что законодательного определения «моббинга» и вообще подобного термина Трудовой кодекс РФ, равно как и другие федеральные законы, в той или иной степени регламентирующие соииально-трудовые отношения, не содержит, а защита личных неимущественных прав работника осуществляется средствами иных отраслей права и, прежде всего, гражданского. Однако нематериальные блага и личные неимущественные права работников не могут в полном объеме составлять сферу регулирования и защитты гражданского права. Вследствие этого в трудовом праве России должны быть легализованы особые способы защиты нематериальных благ работников, для чего требуется проведение единой государственной политики в области охраны достоинства и обеспечения личных трудовых прав работников. При этом меры, направленные на предупреждение «моббинга» и сохранение психического здоровья работников в процессе трудовой деятельности, должны предусматриваться не только на централизованном, но и на локальном уровне правотворчества.

Ключевые слова: психологическая безопасность работников, трудовое законодательство, моральное преследование, личные неимущественные права, гражданское право, моббинг, самозащита, трудовое право, совершенствование, компенсация морального вреда.

ледуя своему предназначению, современное трудовое законодательство обязано учитывать не только темпы развития социальной действительности, но и некоторые ее негативные проявления. В частности, социальная действительность обладает некоторыми явлениями, которым реформы в сфере регулирования трудовых от- ношений, проводимые в современной России, не уделяют внимания. К числу таких социальных явлений, например, следует отнести «моббинг» — моральное преследование работников на рабочем месте в процессе исполнения ими профессиональных обязанностей.

В Федеральном суде Германии по трудовым спорам этот специальный термин 
расшифровывают как «систематическое проявление враждебности, издевательство и дискриминация - как среди работников по найму, так и по отношению к подчиненным со стороны руководства» ${ }^{1}$. Моббинг среди сотрудников одного уровня называют «горизонтальным», а среди работников разных уровней - «вертикальным».

Его особая разновидность - «боссинг» - предусматривает определенное поведение со стороны самого руководителя трудового коллектива, который преследует в качестве цели, как правило, высвобождение от стесняющего работника, хотя, казалось бы, именно руководитель организации должен стремиться поддерживать здоровый психологический климат в своем коллективе для его нормального функционирования. Целенаправленному преследованию или несправедливому отношению со стороны иных лиц может подвергаться и сам руководитель компании или управленец среднего звена.

Согласно терминологии, принятой Международной организацией труда (МОТ), выделяется также понятие «буллинг» персонала. Этот тип агрессии принимает следующие поведенческие формы: крики, оскорбления, неприятие чужой и навязывание своей точки зрения, отсутствие делегирования и сосредоточение полномочий в своих руках, постоянная критика и указания на должностное несоответствие либо на некомпетентность ${ }^{2}$.

Однако в какой бы форме ни выражался моббинг, в т. ч. независимо от того, от какой стороны он исходит - руководства или кол-

1 Что такое «моббинг» и почему на работе плохо? URL: http://www.km.ru (дата обращения: 17.05.2013).

2 Скавитин А. В. Проблема притеснений на рабочих местах (по материалам зарубежных исследований) // Менеджмент в России и за рубежом.- 2004.- № 5.C. 118 . лег, последствия этого явления в целом являются негативными для всех вовлеченных в него лиц. В первую очередь, притеснения на рабочем месте сказываются на здоровье и психическом состоянии «жертвы», во вторую - на сплоченности коллектива, фактической или потенциальной текучести кадров, производительности труда, а значит, и на финансовых показателях.

Так, в июле 2012 года в одной из крупнейших компаний Франции разразился скандал. По официальным данным, 35 человек не выдержали прессинга на работе и наложили на себя руки (в течение последних 5 лет). Во всех предсмертных записках отмечена жестокость, пренебрежительное отношение и невозможность терпеть унижения, которым директор подвергал сотрудников. По утверждению профсоюзов, самоубийств и попыток самоубийства было не меньше $80^{3}$.

Многие авторы признают, что «... труд, приносящий надежный доход, должен быть достойным трудом на основе свободного выбора и уважения личности каждого работника» ${ }^{4}$. В связи с этим мы разделяем позицию А. В. Скавитина, согласно которой моббинг, как негативную составляющую трудовых отношений, «не всегда нужно рассматривать как естественное условие трудовой адаптации, как некие издержки, взамен которых работник получает заработную плату, да еще компенсационный пакет в придачу» ${ }^{5}$.

Согласно проведенному опросу около $80 \%$ сотрудников в одной российской орга-

3 См.: Руководителя французской корпорации обвиняют в доведении сотрудников до самоубийств. URL: http:// www.1tv.ru (дата обращения: 17.05.2013).

4 Шкурко С. Мир труда в канун XXI века: доходы и социальная защита // Трудовое право.- 2002.№ 12.- С. 73 .

5 Скавитин А.В. Указ. соч.- С. 127. 
низации испытывали на себе те или иные проявления моббинга, среди которых: нежелание прислушиваться к предложениям, сокрытие или предоставление неполной информации, предъявление завышенных требований, повышение голоса, обвинение в некомпетентности и т. п. Среди причин подобного поведения указывалось на неприязнь к «новичкам», низкий уровень культуры деловых отношений, привилегированное положение отдельных сотрудников и безнаказанность ${ }^{1}$. Осуществление моббинга может обусловливаться также отсутствием оснований для перевода работников или их увольнения.

В настоящее время в современной России это социальное явление мало изучено. В научной литературе проблема активного преследования личности, занятой трудовой деятельностью, до сих пор мало обсуждается, а вопрос совершенствования законодательства в целях централизованного предупреждения «моббинга» не нашел всестороннего теоретического осмысления. Препятствием на пути защиты личных неимущественных прав в сфере труда может стать то, что законодательного определения «моббинга» и вообще подобного термина Трудовой кодекс РФ, равно как и другие федеральные законы, в той или иной степени регламентирующие социально-трудовые отношения, не содержит ${ }^{2}$. Поскольку каждый десятый в России увольняется из-за причин, связанных с отношениями в коллективе, а каждый двенадцатый может уволиться по этим же причинам, проблему морального преследо-

1 Моббинг: Как выжить в офисных «джунглях». URL: http://emigration.russie.ru (дата обращения: 17.05.2013).

2 Соловьев А. В. Защищает ли работников действующее законодательство от морального преследования на рабочем месте? // Гражданин и право.- 2007.№ 12.- С. 74 . вания работников на своем рабочем месте нельзя оставлять без внимания.

Следует отметить, что на Западе те или иные формы притеснения как отдельная психологическая проблема стали изучаться уже в конце 70-х - начале 80-х годов прошлого века и сейчас в большинстве развитых стран, например, в Германии, Франции, Швеции, зарубежная практика располагает не только необходимой статистической базой, но и специальным законодательством, направленным на противостояние несправедливому отношению и прессингу работодателя, дискриминации в отношении работников, нападкам и притеснениям со стороны коллег по работе. Этими специальными законами предусматривается наказание лиц, виновных в организации, осуществлении моббинга или подстрекательстве к нему3.

Иными словами, достоинство человека давно стало объектом международного регулирования, и зарубежная практика располагает особыми отраслевыми способами его защиты. В основе легализации этих способов защиты лежат положения таких известных актов, как Всеобщая декларация прав человека (1948); Международный Пакт об экономических, социальных и культурных правах (1966); Международный Пакт «О гражданских и политических правах» (1966); Европейская конвенция о защите прав и основных свобод (1950) и др.

Так, преамбула Всеобщей декларации прав человека гласит: «Признание достоинства, присущего всем членам человеческой семьи, и равных и неотъемлемых прав их является основой свободы, справедливости и всеобщего мира». В соответствии с Международным Пактом «О гражданских и политических правах» никто не может

3 Энциклопедия карьеры. URL: http://career.passion.ru (дата обращения: 17.05.2013). 
подвергаться незаконным посягательствам на честь и репутацию (ст. 17). В Конвенции о защите прав человека и основных свобод (ст. 3), а также в Конвенции СНГ о правах и основных свободах человека (ст. 26) сказано: никто не должен подвергаться бесчеловечному или унижающему достоинство обращению или наказанию. Европейская социальная хартия прямо предусматривает право работников на защиту своего достоинства во время работы (ст. 26).

Российская Федерация подписала и ратифицировала Европейскую социальную хартию. Поскольку для Российской Федерации данный документ вступил в силу с 1 декабря 2009 г., перед специалистами в области трудового права и законодателем встал вопрос о содействии предотвращению «издевательских, явно враждебных и оскорбительных действий против отдельных работников на рабочем месте или в связи с работой» и принятии необходимых мер для защиты работников от таких действий (ст. 26 Хартии).

Сегодня, когда в условиях спада экономики часть сотрудников боится остаться без работы, а другая часть готова пойти на любые действия ради карьерного роста, притеснения, психологический прессинг и «прочие проявления патологии межличностных отношений в трудовой сфере» делают актуальными вопросы исследования моббинга для современного трудового права России.

Согласно Конституции Российской Федерации человек, его права и свободы являются высшей ценностью (ст. 2). Ничто не может быть основанием для умаления достоинства личности (ст. 21). Каждый имеет право на ... защиту своей чести и доброго имени (ст. 23). Вслед за Конституцией Трудовой кодекс РФ признает право работников на защиту своего достоинства в период трудовой деятельности (ст. 2). Однако собственного отраслевого механизма защиты лич- ных трудовых благ Трудовой кодекс России не содержит. Более того, среди основных трудовых прав работника в ст. 21 ТК РФ право работника на трудовую честь, достоинство и деловую (профессиональную) репутацию в период его трудовой деятельности не упоминается.

Следует отметить и то, что согласно основным принципам правового регулирования трудовых и иных непосредственно связанных с ними отношений (ст. 2 ТК РФ) каждый работник имеет право на условия труда, отвечающие требованиям безопасности и гигиены. Это конституционное положение (ст. 37 Конституции РФ), как известно, лежит в основе, прежде всего, такого правового института трудового права, как институт охраны труда.

Следует согласиться с В. М. Мелиховым, что «лишь охрана труда в широком ее понятии способна сохранить жизнь и здоровье работников в процессе трудовой деятельности»1. Поэтому система сохранения жизни и здоровья работников под безопасными условиями труда должна подразумевать не только «условия труда, при которых воздействие на работающих вредных и (или) опасных производственных факторов исключено либо уровни их воздействия не превышают установленных нормативов» (ст. 209 ТК), но и условия труда, при которых негативный психологический фактор трудового процесса не будет оказывать решающее влияние на работоспособность и здоровье работника.

Хотелось бы при этом заметить, что психологическая безопасность как правовая категория достаточно нова для российских исследователей и российского законодательства.

1 Трудовое право России: учебник / Под общ. ред. А. Я. Рыженкова. М.: Высшее образование; ЮрайтИздат, 2009.- С. 341. 
Заслуживает внимания позиция ученых, которые психологическую безопасность связывают не столько с «отсутствием угрозы», сколько с состоянием, чувствами и переживаниями человека. С этой точки зрения было сформулировано определение психологической безопасности как состояния общественного сознания, при котором общество в целом и каждая отдельная личность воспринимает существующее качество жизни как адекватное и надежное, поскольку оно создает реальные возможности для удовлетворения естественных и социальных потребностей граждан в настоящем и дает им основания для уверенности в будущем ${ }^{1}$.

Однако в специальной юридической литературе поднимается, прежде всего, вопрос об информационно-психологической безопасности, о влиянии информации на сознание людей и проч. ${ }^{2}$ К сожалению, психологическая защищенность личности в сфере труда, а также юридические методы и средства для ее полноценного обеспечения юридической наукой трудового права не исследуются.

Федеральный закон от 28 декабря 2010 г. № 390-Ф3 «О безопасности» среди основных видов безопасности называет безопасность личности. Поэтому, думается, в целях создания и поддержания необходимого уровня психологической защищенности личности в сфере труда требуется проведение единой государственной политики в области охраны достоинства и обеспечения личных трудовых прав работников.

В настоящее время защита личных неимущественных прав работника осуществ-

1 Рощин С.К. Психологическая безопасность: новый подход к безопасности человека, общества и государства // Российский монитор.- 1995.- № 6.- С. 32.

2 См.: Рыдченко К. Д. Понятие, сущность и содержание информационно-психологической безопасности // Административное право и процесс.- 2009.- № 4.C. 28. ляется средствами иных отраслей права и, прежде всего, гражданского. Так, в соответствии со ст. 152 Гражданского кодекса РФ гражданин вправе требовать по суду опровержения порочащих его честь, достоинство или деловую репутацию сведений, а также возмещения убытков и морального вреда, причиненных их распространением. Однако нематериальные блага и личные неимущественные права работников не могут в полном объеме составлять сферу регулирования и защиты гражданского права ${ }^{3}$.

Трудовой кодекс РФ пока только воспроизводит положения действующего гражданского законодательства, указывая на то, что неправомерные действия или бездействие работодателя, причинившие работнику моральный вред, подлежат возмещению в денежной форме (ст. 237 ТК РФ). В связи с этим специалисты в области трудового права отмечают, что следует расширить сферу применения компенсации морального вреда. В частности, предлагается предусмотреть в Трудовом кодексе РФ компенсацию морального вреда при умалении трудовой чести, в случаях психологического террора — «моббинга» и других случая ${ }^{4}$.

Разъяснениями, содержащимися в пункте 63 Постановления Пленума Верховного Суда РФ от 17 марта 2004 г. № 2 «О применении судами Российской Федерации Трудового кодекса РФ», также подтверждается, что, поскольку Трудовой кодекс РФ не содержит каких-либо ограничений для компенсации морального вреда в случаях нарушения трудовых прав работников, то суд в силу ст.ст. 21

\footnotetext{
3 Алмаева Ю.О. Личные трудовые права работников: проблемы обеспечения и защиты // Правосудие в Татарстане.-2012.- № 3.- С. 36.

4 См.: Шафикова Г. Х. Компенсация морального вреда, причиненного работнику: автореф. дис. ... к.ю.н. Екатеринбург, 2000.- С. 7.
} 
(абз.14 ч.1) и 237 настоящего Кодекса вправе удовлетворить требование работника о компенсации морального вреда, причиненного ему любыми неправомерными действиями или бездействием работодателя.

Таким образом, возможность использовать преимущественно гражданское право в целях защиты прав граждан в личных неимущественных отношениях представляется сомнительной, поскольку «метод правового равенства сторон, свойственный гражданскому праву, не может быть применен к отношениям, где это равенство отсутствует или ограничено» ${ }^{1}$. Вследствие этого в трудовом праве России для улучшения его качества должны быть легализованы особые способы защиты нематериальных благ работников.

Если возникают сомнения относительно целесообразности разработки дополнительных правовых средств данной отраслевой принадлежности, то следует вспомнить, что трудовое право с самого своего появления имело социальное назначение, продиктованное необходимостью защиты экономически более слабого работника от более сильного в любом отношении работодателя. Поэтому в рамках действующего российского трудового законодательства должны присутствовать положения, защищающие, в том числе, психологическое здоровье работников.

Нормы трудового права в этом смысле «призваны дополнить и углубить защиту личных неимущественных прав и других нематериальных благ, осуществляемую гражданским правом, применительно к особенностям трудовых отношений, обеспечить права и свободы человека в период трудовой

1 Лушников А. М., Лушникова М.В. Права работника на защиту трудовой чести и достоинства и обеспечения равенства возможностей на продвижение по работе (теоретико-прикладной анализ ст. 2 ТК РФ) // Трудовое право.— 2009.—№ 2.— С. 108. деятельности...»². В связи с этим целесообразно включение в Трудовой кодекс РФ понятия и права работников на недопущение психологического террора со стороны как должностных лиц, так и коллег по работе 3.

Важную роль в совершенствовании правовой базы для российского трудового права, на наш взгляд, могут сыграть положения трудового законодательства зарубежных стран. Среди основных способов защиты специальный закон о защите работников от морального преследования на рабочем месте, принятый во Франции в 2002 г., называет следующие: 1) приостановление работы работником, если есть разумное основание полагать, что рабочая обстановка представляет для него неминуемую и серьезную опасность, часы простоя при этом подлежат оплате; 2) предупреждение, направление работником соответствующей жалобы о моральном преследовании в представительные органы на предприятии; 3) направление жалобы инспектору труда, который обязан предпринять попытки по примирению сторон конфликта; обращение в суд (бремя доказывания фактов отсутствия морального преследования лежит на работодателе); 4) обращение представителей профсоюзных организаций в суд с иском в защиту работника, подвергшегося моральному преследованию, при условии, что на это имеется его письменное согласие. Суд может переквалифицировать увольнение работника по собственному желанию, подвергшегося моббингу со стороны работодателя, на расторжение трудового договора по вине работодателя со всеми вытекающими в этом случае последствиями ${ }^{4}$.

Как известно, в целях реализации конституционных положений о защите гражданами

2 Киселев И. Я. Новый облик трудового права стран Запада. М., 2003.- С. 44.

3 Шафикова Г. Х. Указ. соч.- С. 11.

4 Лушников А. М., Лушникова М. В. Указ. соч.-С. 111. 
своих прав и свобод Трудовой кодекс в ст. 352 устанавливает основные способы защиты трудовых прав работников: самозащита работниками трудовых прав; защита трудовых прав и законных интересов работников профсоюзами; государственный надзор и контроль в сфере труда; судебная защита.

Статья 379 ТК РФ указывает, что в целях самозащиты трудовых прав работник, известив работодателя или своего непосредственного руководителя либо иного представителя работодателя в письменной форме, может отказаться от выполнения работы, не предусмотренной трудовым договором, а также отказаться от выполнения работы, которая непосредственно угрожает его жизни и здоровью, за исключением случаев, предусмотренных кодексом и иными федеральными законами. Наряду с этим российские работники вправе прибегнуть к самозащите своего права на своевременную и полную выплату заработной платы в случае ее задержки на срок более 15 дней. Данное право реализуется ими путем приостановки работы на весь период до выплаты задержанной суммы (ч. 2 ст. 142 ТК РФ).

Учитывая приведенные положения российского трудового законодательства, а также вышеупомянутый зарубежный опыт, можно предусмотреть в ст. 379 ТК РФ такую форму самозащиты трудовых прав, как отказ от выполнения работы, если рабочая обстановка вследствие морального преследования работника на рабочем месте или в связи с работой непосредственно угрожает его жизни и здоровью. Представляется, что приостановка работы в случае морального преследования работника должна осуществляться лишь после письменного извещения работодателя, хотя на обязательность соблюдения такой процедуры общий порядок использования права на самозащиту не указывает (за исключением отдельного вида самозащиты, предусмотренного для случаев задержки выплаты заработной платы).

Порядок и размер оплаты периода, когда лицо не работает в связи с необходимостью защищать свои трудовые права, следует точно определить. Думается, что поскольку для случаев защиты права на труд, отвечающий требованиям безопасности и гигиены (ст.ст. 219, 220 ТК РФ), установлена оплата за простой не по вине работника (ст. 220 ТК РФ) ${ }^{1}$, это же правило, очевидно, должно действовать и в случае прекращения работы в связи с моральным преследованием на рабочем месте.

Предложенная мера самозащиты видится вполне правомерной и адекватной, т.к. работник вследствие моббинга предпринимает самостоятельные активные действия по охране своих прав, жизни и здоровья, в связи с чем нарушение прав потерпевшего и последствия самозащиты в рассматриваемом случае являются соразмерными. Ведь в результате развернутого психологического подавления, носящего систематический характер, происходит частичная, а иногда и полная утрата работником или группой работников трудоспособности. И речь идет не об отдельных, случайных действиях, направленных против одного работника или группы лиц. Современная действительность демонстрирует длительность, управляемость и целенаправленность процесса моббинга.

Нельзя не обратить внимания и на то, что предоставление более широких возможностей для самозащиты в трудовом праве может встретить различные возражения, поскольку, например, отказ от выполнения работы вследствие морального преследования на рабочем

1 Комментарий к Трудовому кодексу Российской Федерации.-2-е изд., испр., доп. и перераб. / Отв. ред. Ю.П. Орловский. М.: КОНТРАКТ: ИНФРА-М, 2005.C. 989. 
месте может повлечь за собой увольнение этого работника за прогул. Это обусловливается тем, что факт целенаправленного преследования или несправедливого отношения к работникам доказать нелегко. Но, если это получится, то лица, подвергшиеся моральному преследованию в сфере труда, смогут возместить причиненный им в результате этого материальный ущерб и компенсировать моральный вред. Однако в любом случае приостановление работы в случае морального преследования работника следует сочетать с иными способами защиты трудовых прав работников, таких, например, как защита трудовых прав и законных интересов работников профсоюзами и проч.

Согласимся и с тем, что совершенствование правового механизма самозащиты работниками своих трудовых прав будет сдерживаться достаточно низким уровнем правовой активности работников, что объясняется, отчасти, правовым скептицизмом значительной части населения ${ }^{1}$.

ІТаким образом, предоставление более широких возможностей для самозащиты в трудовом праве при условии теоретической проработки этой формы защиты будет содействовать, по нашему мнению, «уменьшению криминализации общества и повышению уровня правовой культуры»². Поэтому полностью исключать возможность самозащиты трудовых прав, в т. ч. в случае морального преследования на рабочем месте, тоже не стоит.

И, наконец, если работнику будет гарантироваться государством, в том числе

1 См.: Канунников А. Б., Пастухов А. А., Канунников С. А. Правовая культура самозащиты работниками трудовых прав // Трудовое право._-2007.№ 2.- C. 51 .

2 Казакова Е. Б. Правовая политика в сфере совершенствования законодательства о самозащите // Правовая политика и правовая жизнь.— 2005.— № 4.— С. 194. и психологическая безопасность в период выполнения им своих трудовых обязанностей, работник наряду с использованием права на самозащиту сможет обратиться в органы Федеральной инспекции труда или органы по рассмотрению индивидуальных трудовых споров. Конечно, потребуются и иные юридические инструменты для борьбы с этим негативным социальным явлением, научная разработка и законодательное оформление которых составляют важную задачу современной науки трудового права.

Однако, на наш взгляд, меры, направленные на предупреждение «моббинга» и сохранение психического здоровья работников в процессе трудовой деятельности, должны предусматриваться не только на централизованном, но и на локальном уровне правотворчества.

В соответствующем правовом акте, регулирующем социально-трудовые отношения в организации или у индивидуального предпринимателя и заключаемом работниками и работодателем в лице их представителей, должны содержаться: положения об этике поведения, запрещающие нецивилизованное поведение должностных лиц по отношению к своим подчиненным; меры ответственности должностных лиц и иных работников, совершающих моббинг; нормы об учете аттестационной (конкурсной) комиссией действительного участия (неучастия) работника в моральном преследовании кого-либо на рабочем месте; меры поощрения должностных лиц за создание справедливых и благоприятных условий труда; ${ }^{3}$ и др.

Трудовым кодексом РФ должна быть предусмотрена обязательность принятия в организации или у индивидуального предпринимателя такого нормативного правового акта, что будет служить основой

3 См.: Соловьев А. В. Указ. соч.- С. 80-81. 
для последующего качественного развития производственных отношений и правовых норм о труде.

Предупреждению моббинга будет служить также разработка и утверждение должностных инструкций. Конечно, должностные инструкции для сотрудников не относятся к числу обязательных документов, и потребность в них определяется работодателем самостоятельно, однако наличие соответствующих инструкций у работодателя достигает необходимые нам цели: работники знают, что должны делать, а работодатель — что и когда с них требовать.

Существенным моментом является то, что должностные инструкции разрабатываются по каждой должности с учетом специфики деятельности конкретной организации или предпринимателя. В должностную инструкцию включаются перечень требований к знаниям работника, квалификационные требования к работнику (образование, стаж работы) и самое главное - перечень обязанностей работника. На практике должностные инструкции дисциплинируют работников, а также служат хорошим доказательством, если возникает трудовой спор о том, что должен знать, уметь и чем именно должен заниматься работник на рабочем месте ${ }^{1}$
Таким образом, хорошая организация труда, четкое разделение труда между отделами или сотрудниками, отсутствие дублирующихся заданий, установление границ служебных полномочий, организация информационных потоков, наличие мотивации у сотрудников и системы кадрового продвижения ${ }^{2}$ и т.д. будут способствовать решению проблемы преследования или несправедливого отношения к работнику в любом трудовом коллективе.

В целом, надо отметить, что включение в систему трудового права России института моббинга, т. е. совокупности правовых норм, направленных на обеспечение прав работников на трудовую честь, достоинство и деловую (профессиональную) репутацию в период их трудовой деятельности, а также направленных на обеспечение условий труда, безопасных для жизни и здоровья работников, обязательных для исполнения работодателями, их должностными лицами и иными работниками, будет иметь, по нашему мнению, лишь позитивное значение в развитии качества правового регулирования труда в современной России и обеспечении психологической безопасности работников в процессе осуществления ими профессиональной деятельности.

\section{Библиография}

1. Что такое «моббинг» и почему на работе плохо? URL: http:/www.km.ru (дата обращения: 17.05.2013).

2. Скавитин А. В. Проблема притеснений на рабочих местах (по материалам зарубежных исследований) // Менеджмент в России и за рубежом.- 2004. - № 5.— С. 118-127.

3. Руководителя французской корпорации обвиняют в доведении сотрудников до самоубийств. URL: http://www.1tv.ru (дата обращения: 17.05.2013).

1 См.: Индивидуальный предприниматель: энциклопедия.- 7-е изд., перераб. и доп. / Под ред. А. В. Касьянова.- ГроссМедиа Ферлаг, РОСБУХ, 2009.- C. 36 .
2 См.: Моббинг: Как выжить в офисных «джунглях». URL: http://emigration.russie.ru (дата обращения: 17.05.2013). 
4. Шкурко С. Мир труда в канун XXI века: доходы и социальная защита // Трудовое право.- 2002.— № 12.— С. 73-74.

5. Моббинг: Как выжить в офисных «джунглях». URL: http://emigration.russie.ru (дата обращения: 17.05.2013).

6. Соловьев А. В. Защищает ли работников действующее законодательство от морального преследования на рабочем месте? // Гражданин и право._ 2007.— № 12.— С. 74-81.

7. Энциклопедия карьеры. URL: http://career.passion.ru (дата обращения: 17.05.2013).

8. Трудовое право России: учебник / Под общ. ред. А. Я. Рыженкова. М.: Высшее образование; Юрайт-Издат, 2009.

9. Рощин С.К. Психологическая безопасность: новый подход к безопасности человека, общества и государства // Российский монитор.- 1995.— № 6.

10. Рыдченко К. Д. Понятие, сущность и содержание информационно-психологической безопасности // Административное право и процесс.— 2009.— № 4.- С. 28-29.

11. Шафикова Г. Х. Компенсация морального вреда, причиненного работнику: автореф. дис. ... к. ю.н. Екатеринбург, 2000.

12. Лушников А. М., Лушникова М.В. Права работника на защиту трудовой чести и достоинства и обеспечения равенства возможностей на продвижение по работе (теоретикоприкладной анализ ст. 2 ТК РФ) // Трудовое право.— 2009.— № 2.- С. 107-112.

13. Киселев И. Я. Новый облик трудового права стран Запада. М., 2003.

14. Комментарий к Трудовому кодексу Российской Федерации.-2-е изд., испр., доп. и перераб. / Отв. ред. Ю. П. Орловский. М.: КОНТРАКТ: ИНФРА-М, 2005.- 1197 с.

15. Канунников А.Б., Пастухов А.А., Канунников С. А. Правовая культура самозащиты работниками трудовых прав // Трудовое право.— 2007.— № 2.- С. 51-54.

16. Казакова Е. Б. Правовая политика в сфере совершенствования законодательства о самозащите // Правовая политика и правовая жизнь.- 2005.— № 4.

17. Индивидуальный предприниматель: энциклопедия.- 7-е изд., перераб. и доп. / Под ред. А. В. Касьянова.- ГроссМедиа Ферлаг, РОСБУХ, 2009.

\section{References (transliterated)}

1. Chto takoe «mobbing» i pochemu na rabote plokho? URL: http://www.km.ru (data obrashcheniya: 17.05.2013).

2. Skavitin A. V. Problema pritesnenii na rabochikh mestakh (po materialam zarubezhnykh issledovanii) // Menedzhment v Rossii i za rubezhom._- 2004._ № 5.- S. 118-127.

3. Rukovoditelya frantsuzskoi korporatsii obvinyayut $\mathrm{v}$ dovedenii sotrudnikov do samoubiistv. URL: http://www.1tv.ru (data obrashcheniya: 17.05.2013).

4. Shkurko S. Mir truda v kanun XXI veka: dokhody i sotsial'naya zashchita // Trudovoe pravo.2002.— № 12.— S. 73-74.

5. Mobbing: Kak vyzhit»v ofisnykh «dzhunglyakh». URL: http://emigration.russie.ru (data obrashcheniya: 17.05.2013).

6. Solov'ev A. V. Zashchishchaet li rabotnikov deistvuyushchee zakonodatel'stvo ot moral'nogo presledovaniya na rabochem meste? // Grazhdanin i pravo.— 2007. - № 12.— S. 74-81.

7. Entsiklopediya kar'ery. URL: http://career.passion.ru (data obrashcheniya: 17.05.2013). 
8. Trudovoe pravo Rossii: uchebnik / Pod obshch. red. A. Ya. Ryzhenkova. M.: Vysshee obrazovanie; Yurait-Izdat, 2009.

9. Roshchin S. K. Psikhologicheskaya bezopasnost': novyi podkhod k bezopasnosti cheloveka, obshchestva i gosudarstva // Rossiiskii monitor.— 1995.—№ 6.

10. Rydchenko K. D. Ponyatie, sushchnost» i soderzhanie informatsionno-psikhologicheskoi bezopasnosti // Administrativnoe pravo i protsess.— 2009.— № 4. - S. 28-29.

11. Shafikova G. Kh. Kompensatsiya moral'nogo vreda, prichinennogo rabotniku: avtoref. dis. ... k.yu.n. Ekaterinburg, 2000.

12. Lushnikov A. M., Lushnikova M. V. Prava rabotnika na zashchitu trudovoi chesti i dostoinstva i obespecheniya ravenstva vozmozhnostei na prodvizhenie po rabote (teoretiko-prikladnoi analiz st. 2 TK RF) // Trudovoe pravo.— 2009.— № 2.— S. 107-112.

13. Kiselev I. Ya. Novyi oblik trudovogo prava stran Zapada. M., 2003.

14. Kommentarii k Trudovomu kodeksu Rossiiskoi Federatsii.— 2-e izd., ispr., dop. i pererab. / Otv. red. Yu.P. Orlovskii. M.: KONTRAKT: INFRA-M, 2005.- 1197 s.

15. Kanunnikov A. B., Pastukhov A. A., Kanunnikov S. A. Pravovaya kul'tura samozashchity rabotnikami trudovykh prav // Trudovoe pravo.— 2007.— № 2.- S. 51-54.

16. Kazakova E. B. Pravovaya politika v sfere sovershenstvovaniya zakonodatel'stva o samozashchite // Pravovaya politika i pravovaya zhizn».- 2005.— № 4 .

17. Individual'nyi predprinimatel': entsiklopediya.- 7-e izd., pererab. i dop. / Pod red. A. V. Kas’yanova.- GrossMedia Ferlag, ROSBUKh, 2009. 